157. Alezander Müllor: Ueber aalesauro Thonerdo des Handels.

(Eingegangen am 14. Juni)

Seit einigen Monaten wird in England und won da aus durch the ganze eivilisirte Welt far ein neaes Desinfectionsmittel, welches wesentlich an Alamininmeblorid besteht, starke Reclame gemacht and dasselbe hauptsächlich in flussiger Form: "Chloralato" schlechtreg and in Pulverform als "Chloralumpowder", nebenbei sber auch als "Chloralumwolle" und "Chloralumwatte" ansgeboten.

Darch die Gate des Hrn. Commerdearath E. Sehering hier bic ich in den Besitz authentischer Proben, sowohl der Lōsang als des Pulvers getommen; ich babe dieselben analysirt and theile nun die Ergebnisse mit.

\title{
d. Chloralum
}

reigte sich als eine dūnne Flüseigkeit von hell öigelber Farbe, von sehwachem, an rohe Salzsāure erinnernden Geruch und von mässig atarker Acjditât; als Zasammenoetznng ergab sich:

$$
\begin{aligned}
& \text { 16,0 Procent Chloralnminium, } \\
& \text { 1,7 - Chlorcalcinm (bezügl -Magnesiam), } \\
& 0,1 \text { - schwefelsaure Alkalien, } \\
& 1,2 \text { - Sulzsăure, } \\
& \text { 19,1 Procent gelöste Bestandtheile wasserfrei, } \\
& \frac{80,9-\text { Wasser }}{100,0 \text { Procent Summa. }}
\end{aligned}
$$

Das rorbandene Chloralumininm (16 Procent der Lösung) eatupricht einem Gemenge von 21 Procent Chlornatrium mit

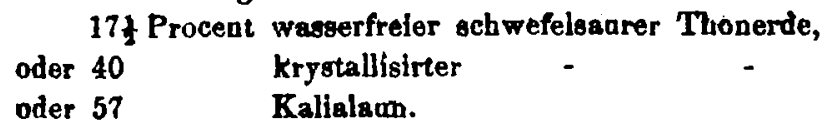

\section{B. Chloralumpowder}

veigte sich als eine weisee, lockere, chlorkalkblhnliche aber gerachlose Masse.

Nach der Analyse berechnet sich folgende Zunammansetzang:

$$
\begin{aligned}
& \text { 20,9 Proeent Wasser, } \\
& \text { 40,7 löslich in Wesser, mirnlich: } \\
& \text { 13,4 Procent Chlarelumininm, } \\
& \text { 4,1 - sohwefotanure Thowerde, } \\
& 8,1 \text { - Bchwefelearrer Kalk, } \\
& \text { 14,1 - echwefelsantes Natron, } \\
& \text { 15,5 in Solzazare lösliche Thonerde, } \\
& \text { 22,9 onl6slich in Salzeāore, nämlich: } \\
& \text { 13,5 Procent Kaolio, wasserfrei, } \\
& 100,0 \text { Procent Summa. } \\
& 9,4 \text { - freie Kieselsăure, }
\end{aligned}
$$


Fluor und Phosphorsâure fand sich nicht vor.

Zweifelsohne steben das flüssige und das feste Chloraluminiumprăparat in einem engen genetiachen Znsammenhang and ebenso sicher dưrften beide als techoische Nebenprodukte anzusprechen seid. Nach den accessorischen Bestandtheilen 20 urtheilen möchte ich dio selben nicht für Nebenprodukte der Thonerdeindustrie als vielmehr der Sodaindustrie balten, und zwar erzeugt zar Verwerthung der Salzgăure.

Thre Heratellang kōnnte in folgender Weise geschehen. Rohe, aber ziemlich eisenfreie Salzssăure läset man unmittelbar auf schwach gerösteten Porzellanthon einwirken. Die resultirende concentrirte Lösung ist das flüssige Chloralaminium. Das ungelöste wird unter Zusatz rnn etwas Chlornatrium and Scbwefelsăure oder dem Rectificationgrückstand der rohen Salzsăure bei gelinder Hitze getrocknes und ist das Chloralumininmpulver.

\section{L. Carins: Uober Absorption von Ozon in Wasser.}

(Ans dem chemischen Institut der Universităt Marburg.)

(Eingegangen am 15. Joni.)

Die Frage, ob Ozon von reinem Wasser in nachpeisbarer Menge gelöst oder, besser gesagt, absorbirt werde, schoint als bigher gans unentschieden betrachtet werden zu müssen, da ron vielen Chemikers webr oder weniger bestimmt behauptet ist, das Ozon sei "unlöslich" in Wasser. Dass das (zon vom Wasser absorbirt werde, ist besonders von Soret") angedeatet; ich babe aie daran gezweifelt, dam dieses in messbarem Verbaltniss geschehe, und zwar, weil bisher vos keinem Gase bekannt geworden ist, dass es (bei sorgfáliger Prüfang) nicht in messbarer Menge rom Wasser absorbirt würde.

Leitet man ozonhailiges Sauerstoffgas bei niederer Temperabur in reines Wasser in einem nicht an weitmöndigen Gefässe, so nimmt das Wasser allmälig den charaktesischen Geruch den Ozons an und giebt slle die gewöbnlichen analytischen Reaktionen des Ozons. Indessen nur, wenn das Gas nicht gar zu arm an Ozon war, lässt sich diese Beobachtung machen; mir war 2 . Th. die That sache schon seit Jahren bekannt, indem ich bei der Darsiellung gro Pserer Mengen ozonbaltigen Sauerstoffe nach der. Methode ron Sorel für die $Z$ wecke der Forlesnog oft Gelegenbeit batte, sie 20 beoback ten. För den vorliegenden $Z$ weck handelte es sich vor Allem daram nachzoweisen, dass das ron Wasser Aufgenommene wirklich Ozol

7) Compt. rend 56, 890. 